\title{
悬 \\ Perfil RDW de cães anêmicos comparado ao VCM e CHCM
}

[RDW profile of anemic dogs compared to $\mathrm{MCV}$ and $\mathrm{MCHC}]$

"Artigo Científico/Scientific Article"

\section{Volnei Rebeque Rodrigues ${ }^{1}$, Sandriele Goes de Campos Deboleto ${ }^{1}$, João Rogério Centenaro² Paulo Henrique Braz ${ }^{2 *}$}

${ }^{1}$ Centro Universitário da Grande Dourados, Dourados-MS, Brasil.

${ }^{2}$ Instituto Federal Farroupilha, Frederido Westphalen-RS, Brasil.

*Autor para correspondência/Corresponding author: E-mail: paulo.braz@iffarroupilha.edu.br

\section{Resumo}

Esta pesquisa teve como objetivo traçar um perfil do RDW de cães anêmicos comparados ao VCM (volume corpuscular médio) e CHCM (concentração de hemoglobina corpuscular média) de acordo com o tipo de anemia apresentada pelos pacientes caninos. Foram observados e tabulados os valores de VG (volume globular), VCM, CHCM e RDW (red cell distribution width/amplitude de distribuição dos glóbulos vermelhos) de 1.247 cães e separados em 4 classes de acordo com o valor do VG: classe 1 (VG abaixo de $25 \%$ ); classe 2 (VG entre 25 e 35\%); classe 3 (VG entre 35 e $45 \%$ ) e classe 4 (VG acima de $45 \%$ ) sendo que destes, 529 foram considerados anêmicos. Os dados foram submetidos à análise de variância, para confirmar possível diferença entre classes para as variáveis VCM e RDW. Houve diferença estatística para VCM e RDW, porém não foi possível observar uma grande dispersão entre as mesmas, para as classes 1 (mais anêmicos) e 2 (menos anêmicos). Assim, pode-se afirmar que os cães se dispuseram de resultados hematimétricos com uma média dispersão de dados, justificados pelos coeficientes de variação do VCM e RDW.

Palavras-chave: anemia; citometria; eritrocitometria; hemograma.

\begin{abstract}
The aim of this research was to outline a RCW profile of anemic animals compared to MCV and MCHC according to the type of anemia presented by canine patients. The values for CV (corpuscular volume), MCV (mean corpuscular volume), MCHC (mean corpuscular hemoglobin concentration) and RDW (red cell distribution width) of 1247 dogs were analyzed and tabulated according to the $\mathrm{CV}$ value: class 1 (CV below $25 \%$ ); class 2 (CV between 25 and 35\%); class 3 (CV between 35 and 45\%), and class 4 (CV above 45\%), of which 529 were considered anemic. Data were submitted to analysis of variance to confirm possible differences between classes for MCV and RDW variables. There was a statistical difference between MCV and RDW, but it was not possible to observe a great dispersion among them, for classes 1 (more anemic) and 2 (less anemic). Thus, it can be stated that the dogs had hematimetric results with an average dispersion of data, justified by the coefficients of variation of the MCV and RDW.
\end{abstract}

Keywords: anemia; blood count; cytometry; erythrocytometry.

\section{Introdução}

O hemograma é considerado um dos exames mais solicitados na rotina laboratorial, devido à sua praticidade, economia e utilidade para o diagnóstico clínico. Pode ser dividido em três partes, constituídas pelo eritrograma, que compreende o hematócrito, dosagem de hemoglobina, avaliação morfológica e contagem total de eritrócito; o leucograma, composto pela avaliação morfológica, contagem total e diferencial de leucócitos; e o plaquetograma, composto da avaliação morfológica e contagem de plaquetas (Lopes et al., 2007; González e Silva, 2008). 
Uma das funções de maior atribuição da investigação do eritrograma é baseada na morfologia e classificação da anemia, definida como a diminuição da contagem dos eritrócitos, da concentração de hemoglobina e do volume globular (Monteiro et al., 2019). A anemia constitui-se raramente em uma doença primária, sendo resultado da manifestação clínica de diversas doenças. Desta forma, é preciso conhecer a causa da anemia, para que o tratamento seja empregado (Lopes et al., 2007).

O RDW (red cell distribution width/amplitude de distribuição dos glóbulos vermelhos) é um índice que avalia o grau de anisocitose das hemácias, representando o coeficiente de variação e seu desvio padrão (Failace et al., 2009) enquanto que o volume corpuscular médio (VCM) avalia o tamanho dos eritrócitos. Por sua vez, os dados da concentração de hemoglobina corpuscular média (CHCM) podem relacionar-se aos defeitos de síntese da hemoglobina, quando reduzidos. Tanto o VCM quanto o CHCM são valores importantes para serem correlacionados para a determinação do tipo de anemia e sua possível causa (Carvalho et al., 2006).

Nesse contexto, o RDW é passível de utilização no diagnóstico de anemia, por meio da avaliação da homogeneidade ou heterogeneidade da população de eritrócitos observada (Januária et al., 2008). Assim, com base em um conjunto de células de aspecto heterogêneo, com diversidade nos tamanhos celulares observados, pode-se suspeitar de um caso de anemia com resposta medular. Isso porque a resposta medular resulta na aceleração da maturação eritrocitária e envio das células sanguíneas em estágio mais avançado para a circulação, podendo liberar hemácias macrocíticas nesse processo (Fleischman, 2012).

Esta pesquisa teve como objetivo traçar um perfil do RDW de animais anêmicos comparados ao VCM e CHCM de acordo com o tipo de anemia apresentada pelos pacientes caninos.

\section{Material e Métodos}

Foi realizada uma análise retrospectiva de prontuários de hemograma no período de dez meses. Os valores foram compilados para quantificação do volume globular (VG), VCM, CHCM e RDW. Obteve-se um total de 1.247 exames de cães atendidos que realizaram hemograma neste período. Os parâmetros mencionados foram obtidos a partir de um contador hematológico automático Sysmex pocH-100iV Diff.

Os dados foram separados em quatro classes: classe 1 - VG abaixo de $25 \%$; classe $2-$ VG entre 25 e $35 \%$; classe $3-$ VG entre 35 e $45 \%$ e classe $4-\mathrm{VG}$ acima de $45 \%$. Tais informações foram submetidas à análise de variância, para verificar se havia diferença entre as classes para as variáveis VCM e RDW. O teste de Tukey foi efetuado para observar se houve diferença significativa entre as classes 1 e 2 (anêmicos) e depois para as classes 3 e 4 (não anêmicos). Para determinação do valor de referência do RDW foram utilizados os valores dos cães não anêmicos pertencentes às classes 3 e 4 a partir do teste de Shapiro-Wilk, para determinar a normalidade dos resultados, obtendo-se um valor de referência para RDW de 12,6 $\pm 3,6$.

Os prontuários dos animais foram analisados para determinação das classes pertencentes e para determinar critérios de exclusão. Foram excluídos do projeto animais internados, recebendo tratamento com fluidoterapia ou medicamentos, a fim de eliminar possíveis alterações hematológicas causadas nestes processos. Nenhuma alteração clínica foi considerada como critério de exclusão.

\section{Resultados e Discussão}

Foram analisados 1.247 prontuários de cães. Com este dado, a separação da quantidade de cães em cada classe e a classificação quanto ao tipo de anemia (Tabela 1).

O VCM e o CHCM são os padrões utilizados para a classificação da anemia baseado no tamanho, que pode ser denominada de macrocítica, normocítica ou microcítica, e na coloração das hemácias que pode ser subscrita em hipocrômica ou normocrômica, o que possibilita distinguir a anemia em regenerativa ou arregenerativa (Braz et al., 2017).

Em pacientes com volume homogêneo de eritrócitos, há um único pico no histograma. No entanto, algumas situações patológicas podem levar a alterações no VCM, que se refletirão em mais picos ou deslocamento do histograma para a esquerda (populações celulares microcíticas) ou para a direita (populações macrocíticas). $\mathrm{Na}$ maioria dos casos, a população eritrocitária anormal coexistirá com a normal (Ravel, 1997), como encontrado neste estudo.

A anemia normocítica normocrômica foi o tipo de anemia predominante, presente em $85 \%$ (449/529) dos casos, dos quais 33,2\% (149/449) 
fazem parte da classe 1 e $66,8 \%$ (300/449) da classe 2. A anemia microcítica normocrômica foi representada por $9,9 \%(52 / 529)$ dos casos, sendo que $42,3 \%$ (22/52) fazem parte da classe 1 e $57,6 \%$ (30/52) da classe 2. A anemia macrocítica normocrômica representou 2,6\% (14/529) dentre os tipos de anemia, sendo que $85,7 \%$ (12/14) fazem parte da classe 1 e $14,3 \%(2 / 14)$ da classe 2 . As duas anemias menos presentes no estudo foram macrocítica hipocrômica com 2,2\% (12/529), e a microcítica hipocrômica, com apenas $0,3 \%$ (2/529), conforme descrito na Tabela 1.

Tabela 1. Classificação do tipo de anemia dos cães, de acordo com os valores encontrados no VCM (volume corpuscular médio) e CHCM (concentração de hemoglobina corpuscular média) separados em classes 1 e 2 , de acordo com a intensidade anêmica.

\begin{tabular}{lccc}
\hline \multicolumn{1}{c}{ Tipo da Anemia } & Classe 1 & Classe 2 & Total \\
\hline Normocítica Normocrômica & $33,2 \%(149 / 449)$ & $66,8 \%(300 / 449)$ & $85 \%(449 / 529)$ \\
Microcítica Normocrômica & $42,3 \%(22 / 52)$ & $57,6 \%(30 / 52)$ & $9,9 \%(52 / 529)$ \\
Macrocítica Normocrômica & $85,7 \%(12 / 14)$ & $14,3 \%(2 / 14)$ & $2,6 \%(14 / 529)$ \\
Macrocítica Hipocrômica & $66,6 \%(8 / 12)$ & $33,3 \%(4 / 12)$ & $2,2 \%(12 / 529)$ \\
Microcítica Hipocrômica & $50,0 \%(1 / 2)$ & $50,0 \%(1 / 2)$ & $0,3 \%(2 / 529)$ \\
Total & $36,3 \%(192 / 529)$ & $63,7(337 / 529)$ & $100 \%(529 / 529)$ \\
\hline
\end{tabular}

Classe 1: VG (volume globular) abaixo de 25\%, classe 2: VG entre 25 e $35 \%$.

Dentre as principais causas da anemia normocítica normocrômica estão hemorragia e hemólise aguda sem tempo para resposta, deficiência de ferro (antes de predominar micrócitos), inflamação, neoplasias crônicas, deficiências endócrinas, aplasia eritroide, hipoplasia e aplasia da medula óssea e intoxicação por chumbo. Já as da macrocítica normocrômica, que são anemias não regenerativas (diminuição do CHCM ainda não está presente), temos deficiência de ácido fólico, FeLV (sem nenhuma reticulocitose), leucemia eritróide e deficiência de vitamina B12 e na microcítica normocrômica quando há doença crônica como por exemplo Doença Renal Crônica (Braz et al., 2015; Godoy et al., 2016; Godoy et al., 2017).

Quando há alterações no diâmetro eritrocitário, correspondentes aos macrócitos e micrócitos circulantes, denomina-se anisocitose eritrocitária (Harold, 2010; Braz et al., 2017). Paralelamente, a RDW tem como proposta oferecer uma resposta confiável da intensidade de anisocitose sem o auxílio da análise microscópica (Hodges e Christopher, 2011; Riond et al., 2011).

Ao analisar os dados dos cães com anemia normocítica normocrômica (Tabela 2), diagnosticada em 85\% (449/529), separados na classe $1(n=149)$, verificou-se que 20,1\% (30/149) apresentaram RDW abaixo da referência, indicativo de arregeneração eritrocícica e 79,9\% (119/149) apresentaram RDW acima da referência, indicando regeneração. Já na classe $2(n=300)$,
$50,7 \%$ (152/300) apresentaram arregeneração eritrocítica e 49,3\% (148/300) regeneração eritrocítica.

A maioria dos cães pertencentes à classe 2 apresentaram a forma mais crítica da anemia, denominada normocítica normocrômica. Embora seja conhecido que defeitos na produção medular como pacientes com insuficiência renal crônica, com a redução da síntese de eritropoetina, a medula óssea não é adequadamente estimulada a produzir eritrócitos gerando um quadro de anemia normocítica normocrômica (Alegre et al., 2009)

Deve ser ressaltado que animais anêmicos, com valor próximo da normalidade, podem apresentar ausência de regeneração celular, pelo fato de a medula óssea ainda não ter sido responsiva à produção celular, devido à fase super aguda em que a doença se encontra, não caracterizando assim uma arregeneração celular (Braz et al., 2017).

Diante da classificação quanto à resposta medular evidente no sangue periférico, e valores em RDW, é possível classificar a anemia em regenerativa e arregenerativa. A forma arregenerativa apresenta prognóstico reservado ou desfavorável, enquanto que a forma regenerativa geralmente é reversível, sendo as principais causas a perda sanguínea [traumas ou cirurgia, CID (coagulação intravascular disseminada)], hemólise (hemoparasitas, anemia autoimune, reação transfusional) (Lopes, 2007; Braz et al., 2015). 
Como segundo maior índice apresentado, a anemia microcítica normocrômica que estava presente em 52 animais, é causada principalmente por doenças crônicas como DRC (doença renal crônica) (Lopes et al., 2007).

Tabela 2. Divisão do valor de RDW (red cell distribution width / amplitude de distribuição dos glóbulos vermelhos) dos cães, separados pela classe de anemia e de acordo com o aumento ou diminuição em comparação ao valor de referência de RDW.

\begin{tabular}{|c|c|c|c|}
\hline \multicolumn{4}{|c|}{ Anemia Normocítica Normocrômica } \\
\hline & RDW acima do valor & RDW abaixo do valor & Total \\
\hline Classe 1 & $79,9 \%(119 / 149)$ & $20,1 \%(30 / 149)$ & $33,2 \%(149 / 449)$ \\
\hline Classe 2 & $49,3 \%(148 / 300)$ & $50,7 \%(152 / 300)$ & $66,8 \%(300 / 449)$ \\
\hline Total & $59,5 \%(267 / 449)$ & $40,5 \%(182 / 449)$ & $100 \%(449 / 449)$ \\
\hline \multicolumn{4}{|c|}{ Anemia Microcítica Normocrômica } \\
\hline Classe 1 & $90,9 \%(20 / 22)$ & $9,1 \%(2 / 22)$ & $42,3 \%(22 / 52)$ \\
\hline Classe 2 & $73,3 \%(22 / 30)$ & $26,7 \%(8 / 30)$ & $57,7 \%(30 / 52)$ \\
\hline Total & $80,8 \%(42 / 52)$ & $19,2 \%(10 / 52)$ & $100 \%(52 / 52)$ \\
\hline \multicolumn{4}{|c|}{ Anemia Macrocítica Normocrômica } \\
\hline Classe 1 & $100 \%(12 / 12)$ & $0 \%(0 / 12)$ & $85,8 \%(12 / 14)$ \\
\hline Classe 2 & $50 \%(1 / 2)$ & $50 \%(1 / 12)$ & $14,2 \%(2 / 14)$ \\
\hline Total & $92,9 \%(13 / 14)$ & $7,1 \%(1 / 14)$ & $100 \%(14 / 14)$ \\
\hline \multicolumn{4}{|c|}{ Anemia Macrocítica Hipocrômica } \\
\hline Classe 1 & $100 \%(8 / 8)$ & $0 \%(0 / 8)$ & $66,6 \%(8 / 12)$ \\
\hline Classe 2 & $100 \%(4 / 4)$ & $0 \%(0 / 4)$ & $33,3 \%(4 / 12)$ \\
\hline Total & $100 \%(12 / 12)$ & $0 \%(0 / 12)$ & $100 \%(12)$ \\
\hline \multicolumn{4}{|c|}{ Anemia Microcítica Hipocrômica } \\
\hline Classe 1 & $100 \%(1 / 1)$ & $0 \%(0)$ & $50 \%(1 / 2)$ \\
\hline Classe 2 & $100 \%(1 / 1)$ & $0 \%(0 / 1)$ & $50 \%(1 / 2)$ \\
\hline Total & $100 \%(2)$ & $0 \%(0)$ & $100 \%(2)$ \\
\hline
\end{tabular}

Classe 1: VG (volume globular) abaixo de 25\%, classe 2: VG entre 25 e 35\%. Valores de referência variam de 11 a $14 \%$.

A partir do RDW demonstrado na classe 1, 90,9\% (20/22) dos casos eram anemias regenerativas e $9,1 \% \quad(2 / 22)$ arregenerativas, enquanto que na classe $2, \quad 73,3 \% \quad(22 / 30)$ apresentaram anemia regenerativas e $26,7 \%(8 / 30)$ arregenerativas (Tabela 2). Pode-se considerar que uma fração dos animais oriundos de exames clínicos apresentava alguma alteração patológica crônica.

As variações de RDW podem indicar anemia, diabetes ou problemas hepáticos. Quando abaixo dos valores de referência, geralmente não indicam alterações clínicas, se interpretado de forma isolada. Já aumentado, podem sugerir anemia por deficiência de ferro, megaloblástica, talassemia, ou doenças hepáticas. Essas variações ocorrem devido à má distribuição de eritrócitos de maneira devida.

Já a sua apresentação em valores condizentes com a referência pode indicar um prognóstico ruim, pois não há amplitude de distribuição de eritrócitos (anemia arregenerativa, causada por lesões na medula óssea ou ausência de elementos necessários para a produção de eritrócitos, se caracterizando por anemias normocíticas normocrômicas). Em casos em que a anemia se demonstra normocítica normocrômica e apresentam RDW acima de sua referência, preconiza-se que o paciente se reabilite adequadamente (Matos et al., 2008).

A anemia macrocítica normocrômica, observada em 14 cães, ocorre devido a uma eritropoiese defeituosa (possivelmente doenças renais, hipoplasia ou aplasia medular e agentes infecciosos em geral), podendo ser revertida. Essa alteração pode ocorrer pelo fato desta estar associada às doenças inflamatórias, visto que nessa condição, ocorre a liberação de citocinas inflamatórias, as quais geram um encurtamento da vida dos eritrócitos, causando a supracitada anemia (Failace, 2015).

Na classe 2 foi observado $50 \%$ (1/2) de cães com arregeneração e 50\% (1/2) com regeneração. Observando a classe $1,85,8 \%(12 / 14)$ dos cães indicam uma resposta regenerativa, ou seja, com o RDW acima do valor de referência. Essa anemia apresentada pode ser regenerativa devido à perda sanguínea, babesiose (causa destruição dos glóbulos vermelhos) ou hemólise.

Gonçalves et al. (2014) afirmaram que o grau de anemia e de reticulocitose alteram de forma distinta os valores de RDW e de VCM de cães. Existe uma relação significativa entre o VCM e o RDW, sendo assim, sensíveis para indicação da 
heterogeneidade da população de eritrócitos, também nos casos de microcitose (Monteiro, 2010). Como apresentado na Tabela 3, letras distintas na mesma linha indicam diferença estatística, tanto para VCM quanto para RDW. Tendo deste modo, cães com índices hematológicos imensamente abaixo dos níveis de referência, tal como, houve cães com significativo aumento de seus índices hematológicos, justificados pelos coeficientes de variação do VCM (16.77\%) e RDW (22.87\%). Assim sendo o RDW é um indicador de anisocitose mais sensível que o VCM e seu valor é diretamente proporcional ao grau de anemia e reticulocitose (Gonçalves et al., 2014).

Tabela 3. Análise de variância de classes para as variáveis VCM e RDW.

\begin{tabular}{lccc} 
& Classe 1 & Classe 2 & CV \\
\hline VCM & $64.88906_{\mathrm{a}}$ & $61.73501_{\mathrm{b}}$ & $16,77 \%$ \\
RDW & $17.96042_{\mathrm{a}}$ & $14.95964_{\mathrm{b}}$ & $22,88 \%$ \\
\hline
\end{tabular}

VCM: volume corpuscular médio, RDW: amplitude de distribuição dos eritrócitos, CV: coeficiente de variação, classe 1: VG (volume globular) abaixo de $25 \%$, classe $2:$ VG entre 25 e $35 \%$. Letras minúsculas diferentes na mesma linha, diferem-se estatisticamente pelo teste de Tukey $(\mathrm{p}<0,05 \%)$, proporcional ao grau de anemia e reticulocitose.

$\mathrm{Na}$ anemia macrocítica hipocrômica, onde ocorre anisocitose por macrocitose e policromia por hipocromia, $66,6 \%(8 / 12)$ estão na classe $1 \mathrm{e}$ $33,3 \%(4 / 12)$ na classe 2. Já na anemia microcítica hipocrômica, em que ocorre anisocitose por microcitose e policromia por hipocromia, $50 \%$ $(1 / 2)$ estão na classe 1 e $50 \%(1 / 2)$ na classe 2. Nestes dois tipos de anemia, não foi observado nenhum tipo de resposta arregenerativa.

Quando comparadas as classes 1 e 2 (grupo anêmico) com as classes 3 e 4 (grupo controle não anêmico) foi observada diferença estatística, utilizando-se teste do Tukey, com um coeficiente de variação de $19,1 \%$ que, segundo a classificação de Pimentel-Gomes (1985), indicou uma média dispersão dos dados, demonstrando variância nas amostras de VCM e RDW.

\section{Conclusão}

O RDW apresenta uma resposta superior ao VCM e CHCM ao determinar a intensidade de anisocitose, sendo que, quanto mais alto for o índice demonstrado, maiores serão as chances de o animal apresentar regeneração. Houve marcante diferença estatística ao comparar valores de VCM com o RDW, porém não foi possível observar grande dispersão entre as mesmas para as classes 1 (mais anêmicos) e classe 2 (menos anêmicos). Assim, pode-se afirmar que os animais se dispuseram de resultados hematimétricos com uma média dispersão de dados, justificados pelos coeficientes de variação do VCM e RDW.

\section{Conflito de Interesse}

Os autores declaram não existir conflito de interesse.

\section{Comitê de Ética}

$\mathrm{O}$ projeto de pesquisa foi aprovado pelo comitê de ética CEUA-UNIGRAN - Centro Universitário da Grande Dourados, sob o número 018/17.

\section{Referências}

Alegre, S.M.; Carvalho, O.M.F. Como diagnosticar e tratar anemias. Revista Brasileira de Medicina, 66(8): 41-50, 2009.

Braz, P.H.; Sartoretto, M.C.; Souza, A.S.; Melo, F.M.G. Hematological abnormalities in dogs naturally infected by Leishmania spp. Acta Veterinária Brasílica, 1(9): 87-90, 2015.

Braz, P.H.; Sartoretto, M.C.; Souza, A.S.; Siqueira, M.S. Comparação entre os valores da amplitude de distribuição de diâmetro dos eritrócitos e do volume corpuscular médio com a citometria de eritrócitos em cães com leishmaniose. Pesquisa Veterinária Brasileira, 37(7): 781-784, 2017.

Carvalho, M.C.; Baracat, E.C.E.; Sgarbieri, V.C. Anemia ferropriva e anemia de doença crônica: distúrbios do metabolismo de ferro. Revista de Segurança Alimentar e Nutricional, 13(2): 54-63, 2006.

Failace, R.; Fernandes, F.B.; Failace, R. Hemograma: manual de interpretações. $6^{\mathrm{a}}$ ed. Porto Alegre: Artmed, 2015. 482p.

Fleischman, W. Anemia: determining the cause. Compendium on Continuing Education for the Practising Veterinarian, 34(6): E1, 2012.

Godoy, K.C.S; Braz, P.H.; Assis, A.R.; Antunes, T.R.; Gomes, D.C.; Souza, A.I. Avaliação dos indicadores de lesão miocárdica em cães com leishmaniose visceral. Arquivo Brasileiro de 
Medicina Veterinária e Zootecnia, 68(2): 313-320, 2016.

Godoy, K.C.S.; Antunes, T.R.; Braz, P.H.; Assis, A.R.; Oliveira, G.G.; Silveira, A.W.; Souza, A.I. Comportamento dos marcadores laboratoriais de injúria renal em cães com leishmaniose visceral. Pesquisa Veterinária Brasileira, 37(11): 85-87, 2017.

Gonçalves, D.S.; Almeida, B.F.M.; Bomfim, S.R.M.; Ciarlini, P.C. Variação da distribuição do diâmetro eritrocitário e do volume corpuscular médio em cães anêmicos. ARS Veterinária, 30(2): 115-119, 2014.

González, F.H.D.; Silva, S.C. Avaliação da hemostasia e distúrbios da coagulação. Patologia Clínica Veterinária, 1(1): 58-72, 2008.

Harold, T. Laboratory and clinical diagnosis of anemia. Schalm's Veterinary Hematology, 1(6): 152-161, 2010.

Hodges, J.; Christopher M.M. Diagnostic accuracy of using erythrocyte indices and polychromasia to identify regenerative anemia in dogs. Journal of the American Veterinary Medical Association, 238(11): 1352-1458, 2011.

Januária, F.M.; Carvalho, M.G.; Dusse, L.M.S.; Ferreira, M.F.R.; Stubbert, R.V.B. O papel do RDW, da morfologia eritrocitária e de parâmetros plaquetários na diferenciação entre anemias microcíticas e hipocrômicas. Revista Brasileira de Hematologia e Hemoterapia, 30(6): 463-469, 2008.
Lopes, S.T.A.; Biondo, A.W.; Santos, A.P.; Emanuelli, M.P.; Antoniazzi, A.Q.; Valle S.F. Manual de Patologia Clínica Veterinária. $3^{\mathrm{a}}$ ed. Santa Maria: UFSM, 2007. 107p.

Matos, J. F.; Dusse, L. M. S.; Stubbert, R. V. B.; Lages, G. F. G.; Carvalho, M. G. Índice de anisocitose eritrocitária (RDW): diferenciação das anemias microcíticas e hipocrômicas. Revista Brasileira de Hematologia e Hemoterapia, 30(2): 120-123, 2008.

Monteiro, L. Valores de referência do RDW-CV e do RDW-SD e sua relação com o VCM entre os pacientes atendidos no ambulatório do Hospital Universitário Oswaldo Cruz - Recife, PE. Revista Brasileira de Hematologia e Hemoterapia, 32(1): 34-39, 2010.

Monteiro, M.D.; Ferreira, N.F.; Marins, F.R. Anemia megaloblástica: revisão de literatura. Revista Saúde em Foco, 11(1): 934-963, 2019.

Pimentel-Gomes, F. Curso de estatística experimental. $15^{\mathrm{a}}$ ed. Piracicaba: Editora FEALQ, 2009. $451 \mathrm{p}$.

Ravel, R. Laboratório clínico: aplicação clínica dos dados laboratoriais, $6^{\text {a }}$ ed. Rio de Janeiro: Guanabara Koogan, 1997. 616 p.

Riond, B.; Weissenbacher, S.; Hofmann-Lehmann, R.; Lutz, H. Performance evaluation of the Symex pocH-100Iv Diff hematology analyzer for analysis of canine, feline, equine and bovine blood. Veterinary Clinical Pathology, 40: 484-395, 2011. 